\title{
Коррозионная стойкость бетонов с заполнителем из уртита
}

\author{
Белогурова Т.П. ${ }^{1}$, Нерадовский Ю.Н. ${ }^{2}$, Беляевский А.Т. ${ }^{1}$ \\ ${ }^{1}$ Институт химии и технологии редких элементов и минерального сырья им. И.В. Тананаева КНЦРАН, \\ Anamumbl,t.belogurova@ksc.ru \\ ${ }^{2}$ Геологический институт КНЦ РАН, Anaтиты, nerad@geoksc.apatity.ru
}

Аннотация. Оценена стойкость бетонов с заполнителем из уртита в жидких агрессивных средах с повышенным содержанием ионов $\mathrm{Cl}^{-}, \mathrm{SO}_{4}^{2-}$ и $\mathrm{NO}_{3}^{-}$. Показано, что после 1 года испытаний исследованные материалы обладают коррозионной стойкостью по отношению к указанным средам. Микроскопическими исследованиями структуры бетонов после испытаний установлено, что главные минеральные фазы уртита - нефелин и эгирин - не проявили взаимодействия с агрессивной средой. Нефелиновый заполнитель, благодаря повышенной активности по отношению к гидроксиду кальция в сравнении с кварцевым песком, обеспечивает более плотную контактную зону заполнителя с цементной матрицей, что способствует повышению коррозионной стойкости бетонов.

Ключевые слова: уртит, свойства, коррозионная стойкость, жидкие агрессивные среды, микроскопические исследования.

\section{The corrosion resistance of concrete with a urtite aggregate}

\author{
Belogurova T.P. ${ }^{1}$, Neradovsky Y.N. ${ }^{2}$, Belyaevsky A.T. ${ }^{1}$ \\ ${ }^{\prime}$ I.V. Tananaev Institute of Chemistry and Technology of Rare Elements and Mineral Raw Materials of the Kola \\ Science Centre, RAS, Apatity, t.belogurova@ksc.ru \\ ${ }^{2}$ Geological Institute of the Kola Science Centre, RAS, Apatity, nerad@geoksc.apatity.ru
}

\begin{abstract}
The stability of concrete with a urtite aggregate in a liquid aggressive media with an increased content of $\mathrm{Cl}^{-}, \mathrm{SO}_{4}^{2-}$ and $\mathrm{NO}_{3}^{-}$ions was evaluated. It is shown that after 1 year of testing, the studied materials have corrosion resistance in relation to the specified media. Microscopic studies of the structure of concrete after testing showed that the main mineral phases of urtite - nepheline and aegirine - did not show interaction with an aggressive environment. Nepheline aggregate, due to its increased activity with respect to calcium hydroxide in comparison to quartz sand, provides a more dense contact zone of the aggregate with the cement matrix, which helps to increase the corrosion resistance of the concrete.
\end{abstract}

Key words: urtite, properties, corrosion resistance, liquid aggressive media, microscopic examination.

\section{Введение}

Вскрышные породы рудников АО «Апатит» не находят практического применения в строительстве из-за повышенного содержания в их составе нефелина, относящегося по действующим стандартам к вредным примесям. Ранее проведенные исследования нефелинсодержащих пород позволили рекомендовать их для получения бетонных изделий, эксплуатирующихся в неагрессивных условиях (Белогурова и др., 2004). Приведенные в работе (Белогурова и др., 2019) результаты по исследованию коррозионной стойкости уртитов и заполнителей на их основе в различных агрессивных средах свидетельствуют о достаточной стойкости этих материалов. Микроскопическими исследованиями структуры уртитов после испытаний установлено, что в образцах следов растворения минералов не наблюдается и признаков коррозии породы не обнаружено. В представленной работе приводятся результаты исследований коррозионной стойкости бетонов на основе уртитового заполнителя в жидких средах, что позволит научно обосновывать возможности использования нефелинсодержащих пород для получения бетонов различного назначения.

\section{Материалы и методика исследований}

Коррозионная стойкость бетонов изучалась на образцах-балочках размером $2 \times 2 \times 10$ см.

Образцы изготавливались на цементе марки ЦЕМ I 52.5Н (г. Стерлитамак). В качестве заполнителей мелкозернистого бетона использовались отсевы дробления фракции 0-5 мм уртита рудни- 
ка «Восточный» (У). Для сравнительных экспериментов применялись традиционные заполнители из отсевов дробления гранита фракции 0-5 мм месторождения «Кузрека» (Г) и природный песок карьера «Большая Лавна» с $\mathrm{M}_{\text {кр }}=2.3$ (П). В работе использовался гранулометрический состав отсевов дробления пород и песка в соотношении (2.5-5):(0-2.5) $=2: 1$. В качестве минеральной добавки использовалась зола Апатитской ТЭЦ в количестве $15 \%$ от массы цемента в части его замены для составов на уртите (УЗ) и граните (ГЗ).

В исследованиях использовались 3 жидкие агрессивные среды: хлоридная с концентрацией ионов $\mathrm{CI}^{-}=150$ мг/л, сульфатная с концентрацией ионов $\mathrm{SO}_{4}{ }^{2-}=1500$ мг/л, азотнокислая с концентрацией ионов $\mathrm{NO}_{3}^{-}=3500$ мг/л. В качестве неагрессивной среды применяли дистиллированную воду. Смена жидкостей проводилась каждые 3 недели.

Для каждого вида заполнителя было изготовлено по 96 балочек, половина из которых подвергались тепловлажностной обработке (ТО) с выдержкой в пропарочной камере в течение 6 часов при температуре $85^{\circ} \mathrm{C}$, остальные твердели в нормальных условиях (НT) при температуре $20 \pm 2{ }^{\circ} \mathrm{C}$ и относительной влажности 70-80 \%. Перед коррозионными испытаниями определялась средняя начальная прочность бетона на изгиб и сжатие по показателям 10 и 20 образцов соответственно. Через каждые 6 месяцев испытаний в агрессивных средах образцы подвергались внешнему осмотру, испытаниям на прочность при изгибе и сжатии, а также изучению состава (РФА, ДТА) и микроструктуры контактной зоны (МБС-10, Ультрафот-3, СЭМ).

\section{Полученные результаты и обсуждение}

В таблице 1 представлены результаты испытания прочности бетонных образцов нормального твердения (НТ) и после тепловой обработки (ТО) на изгиб, находившихся в различных жидких лабораторных средах в течение 1 года.

Таблица 1. Прочность при изгибе образцов бетона, МПа, после 1 года испытаний.

Table 1. Bending strength of concrete samples, MPa, after 1 year of testing.

\begin{tabular}{|c|c|c|c|c|c|c|c|c|c|c|}
\hline \multirow{3}{*}{ Среда } & \multicolumn{10}{|c|}{ Составы, условия твердения } \\
\hline & \multicolumn{2}{|c|}{$\mathrm{y}$} & \multicolumn{2}{|c|}{ у3 } & \multicolumn{2}{|c|}{$\Gamma$} & \multicolumn{2}{|c|}{$\Gamma 3$} & \multicolumn{2}{|c|}{$\Pi$} \\
\hline & HT & TO & HT & TO & HT & TO & HT & TO & HT & TO \\
\hline До испытаний & 8.3 & 9.0 & 8.5 & 9.4 & 7.2 & 8.1 & 7.9 & 8.8 & 6.9 & 8.4 \\
\hline I - д. в. & 12.2 & 10.3 & 9.6 & 8.7 & 10.1 & 8.2 & 8.6 & 9.3 & 8.3 & 7.2 \\
\hline $\mathrm{II}-\mathrm{Cl}^{-}$ & 10.8 & 9.5 & 11.2 & 10.1 & 9.5 & 9.5 & 7.7 & 10.5 & 9.6 & 8.6 \\
\hline $\mathrm{III}-\mathrm{SO}_{4}^{2-}$ & 8.6 & 7.1 & 8.8 & 10.5 & 8.9 & 8.1 & 8.8 & 7.9 & 7.6 & 6.8 \\
\hline $\mathrm{IV}-\mathrm{NO}_{3}^{-}$ & 9.5 & 8.9 & 9.1 & 9.8 & 7.6 & 8.7 & 8.2 & 8.3 & 7.0 & 8.4 \\
\hline
\end{tabular}

Анализ данных показывает, что наименьшие значения прочности образцов нормального твердения отмечаются у состава на песке (П-НТ), наибольшие - у состава на уртите с золой (УЗ-НТ). Прочностные показатели бетонов, твердевших при тепловой обработке (ТО), в целом больше, чем у бетонов нормального твердения (НТ). Через 1 год прочностные показатели несколько снизились по сравнению с испытаниями в 6 месяцев, однако, остались выше первоначальных значений. Наибольший прирост прочности отмечается у бетона состава У-НТ в дистиллированной воде (коэф. стойкости $\left.\mathrm{KC}_{360}=1.47\right)$, наименьший - у бетона состава П-НТ в азотнокислой среде $\left(\mathrm{KC}_{360}=1.01\right)$.

Прочность образцов при сжатии после 6 и 12 месяцев воздействия агрессивных сред имеют ту же тенденцию, что и при изгибе. После 12 месяцев испытаний ни у одной партии бетона не снизились показания прочности по сравнению с ее значениями до коррозионных испытаний, а увеличились в среднем на 1.6-18.8 \%. Таким образом, прочностными испытаниями установлено, что во всех жидких средах бетоны на всех видах заполнителей увеличили значения прочности как при изгибе, так и при сжатии, что свидетельствует о коррозионной стойкости исследуемых бетонов в данных средах после 12 месяцев испытаний.

Внутренняя структура бетонов, изучалась с помощью микроскопа Ультрафот-3 (Opton) на полированных образцах, подвергшихся воздействию различных жидких сред. На рисунке 1 приведе- 

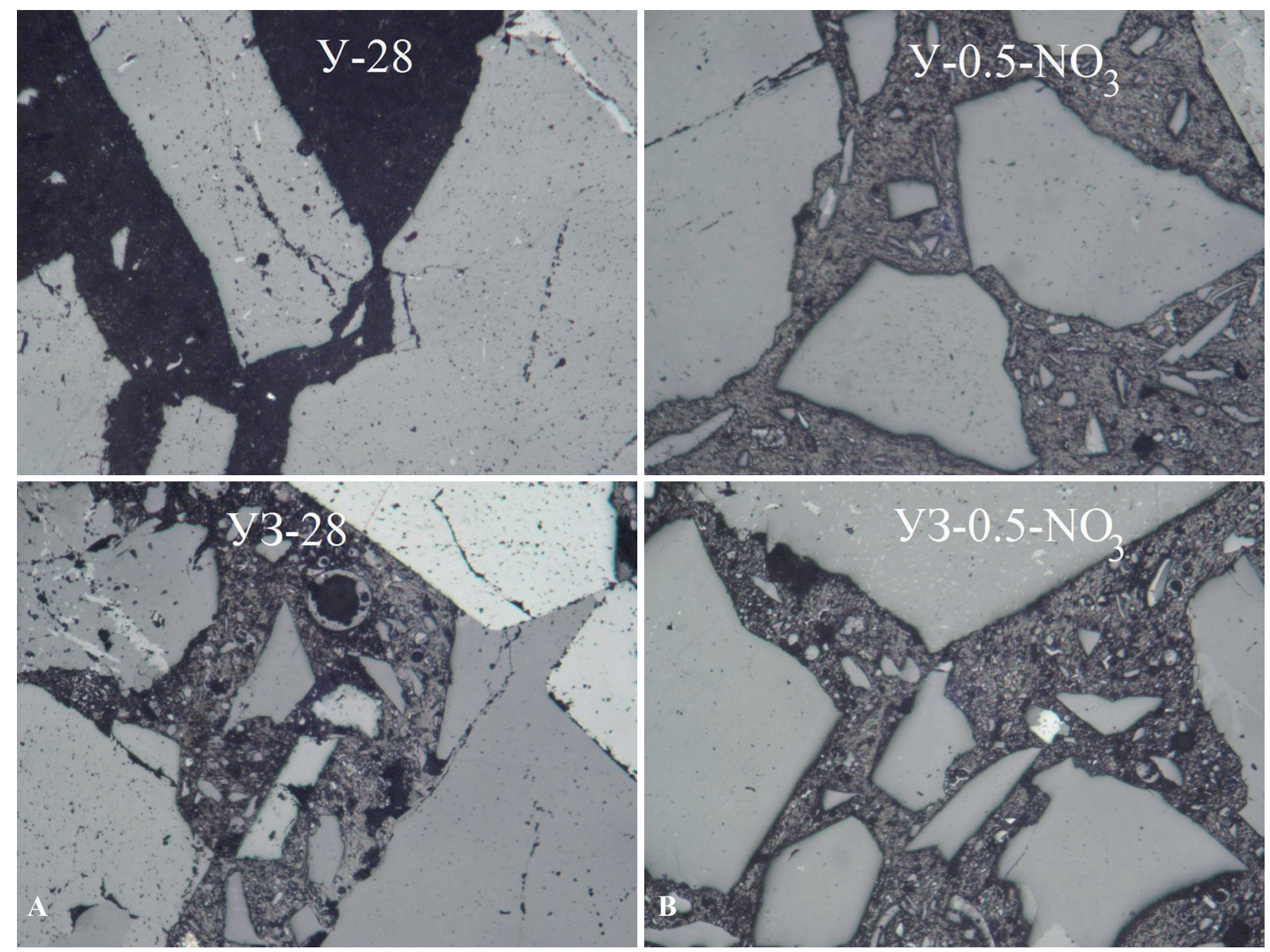

Рис. 1. Контактная зона зерен минералов и пород (светлое) в цементном тесте (черное) в образцах бетона до испытаний (А) и после 0.5 года воздействия азотной кислоты (В). Размер поля 1.6 мм. Фото в отраженном свете на микроскопе Ультрафот 3.

Fig. 1. Contact zone of mineral and rock grains (light) in the cement test (black) in concrete samples before testing (A) and after 0.5 years of exposure to nitric acid (B). Field size is $1.6 \mathrm{~mm}$. Photo in reflected light using the Ultraphot 3 microscope.

ны фото образцов бетонов с заполнителем из уртита до испытаний и после 6 месяцев воздействия раствора азотной кислоты.

Исследованиями установлено, что все представленные образцы имеют плотную структуру с четко выраженным контактом заполнителя с цементом. На фото отчетливо виден полиминеральный характер уртита, включающий нефелин, эгирин, титанит и другие минералы. Добавка золы прослеживается в образцах УЗ в виде сферических включений. Наглядно видно, что добавка улучшает полируемость образцов (цементный камень светлеет), то есть структура бетонов становится прочнее, что согласуется с результатами прочностных испытаний. В образцах бетонов после воздействия азотной кислоты в зоне контакта заполнителя с цементом наблюдается так называемая «реакционная кайма», свидетельствующая о происходящих химических процессах в зоне контакта (Белогурова и др., 1990; Крашенинников и др., 1989). В целом микроскопическими исследованиями не выявлено каких-либо деструктивных изменений, связанных с взаимодействием минеральных фаз на границе наполнителя и цемента, ни у одного из представленных образцов.

Процессы, происходящие в контактной зоне, изучались с помощью цифрового сканирующего электронного микроскопа SEM LEO-420 на образцах бетонов, хранившихся 0.5 года в агрессивных средах. На рисунке 2 представлены фото сколов поверхностей образцов бетонов на уртите, уртите с золой, граните и граните с золой после 0.5 года воздействия азотной кислоты. 
На снимках видно, что у всех заполнителей наблюдается прочный контакт с цементной матрицей, который представлен тонким слоем гидратных фаз, образующихся в результате взаимодействия поверхности заполнителя с гидроксидом кальция. Образцы бетона имеют сильно развитую контактную поверхность, сплошь покрытую новообразованиями различного состава. Так, в зоне контакта уртита с цементной матрицей четко прослеживается слой гидросиликатного геля. В контактной зоне гранита и на его поверхности наблюдается мелкодисперсная гидратированная масса кристаллов эттрингита и крупных агрегатов пластинчатых кристаллов портландита. При введении микронаполнителя в виде золы на микроснимках визуально наблюдается уплотнение контактной зоны как у уртита, так и у гранита. В зоне контакта появляется большое количество новообразований различного состава - от геля кремнекислоты до сферических сростков тонкоигольчатых кристаллов гидросиликатных и гидроалюминатных соединений.

Данные новообразования также накапливаются в порах цемента, заполняя их и способствуя уплотнению структуры цементного камня. На рисунке 3 А видно, что после 0.5 года воздействия азотной кислоты в поре бетона на уртитовом заполнителе образовалась мелкокристаллическая сотовая структура гелеобразных гидратных соединений, характерных для кремниевой кислоты (Рахимбаев и др., 2011).

Ортокремниевая кислота $\mathrm{H}_{4} \mathrm{SiO}_{4}$ не является агрессивной по отношению к бетону, а имеет родственный с ним химический состав, что, вероятно, повышает коррозионную стойкость бетонов в кислой среде.

На рисунке 3 В и С в порах цементного камня отчетливо видны достаточно крупные волокнистые кристаллы гидросиликатов, гидросульфоалюминатов и других комплексных солей кальция, которые могут расти направленно, образуя определенно ориентированные текстуры в виде игольча-
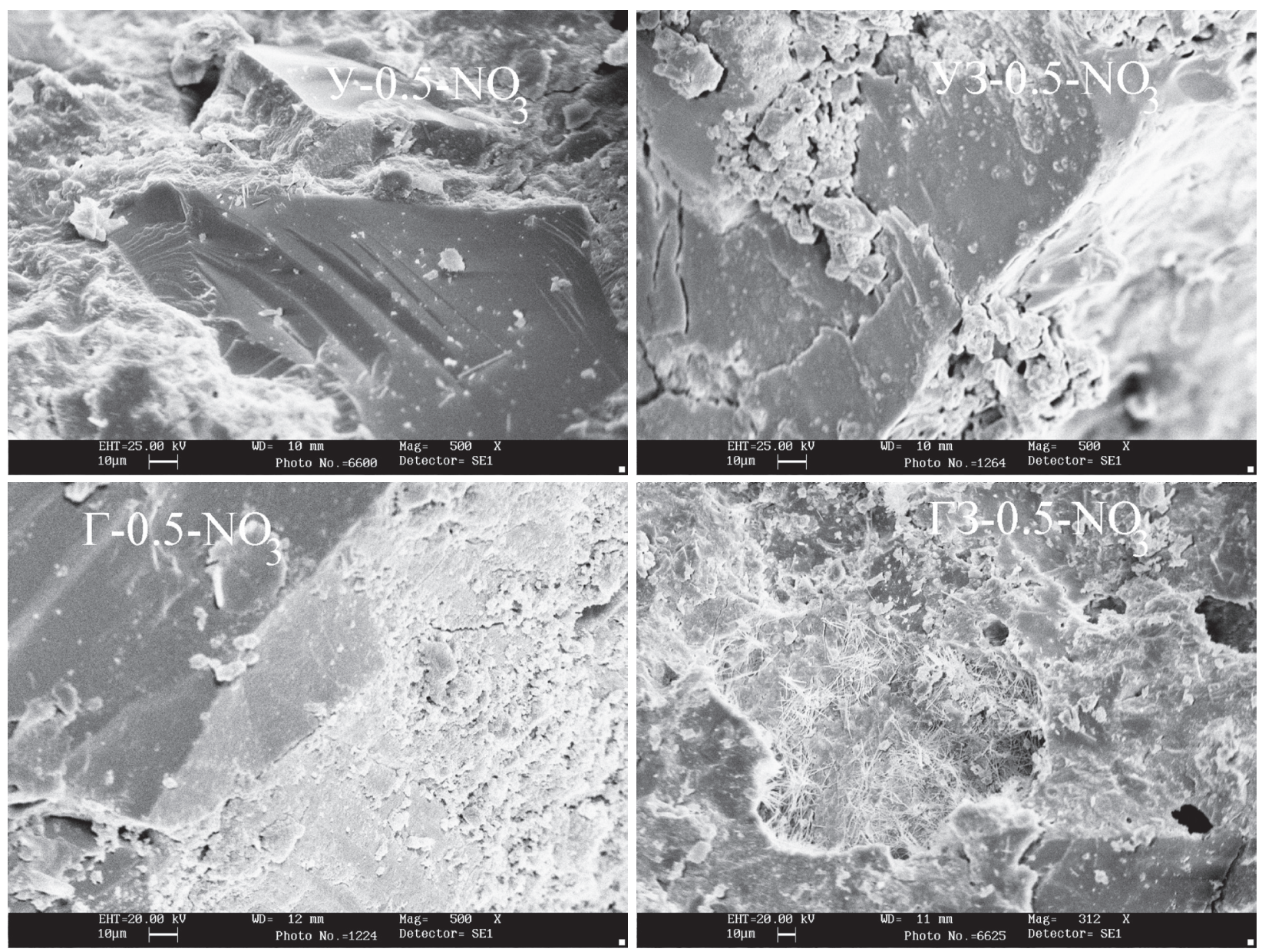

Рис. 2. Микроструктура бетона после 0.5 года воздействия азотной кислоты (SEM LEO-420). Увеличение 500.

Fig. 2 - Microstructure of the concrete after 0.5 years of exposure to nitric acid (SEM LEO-420). Magnification 500. 

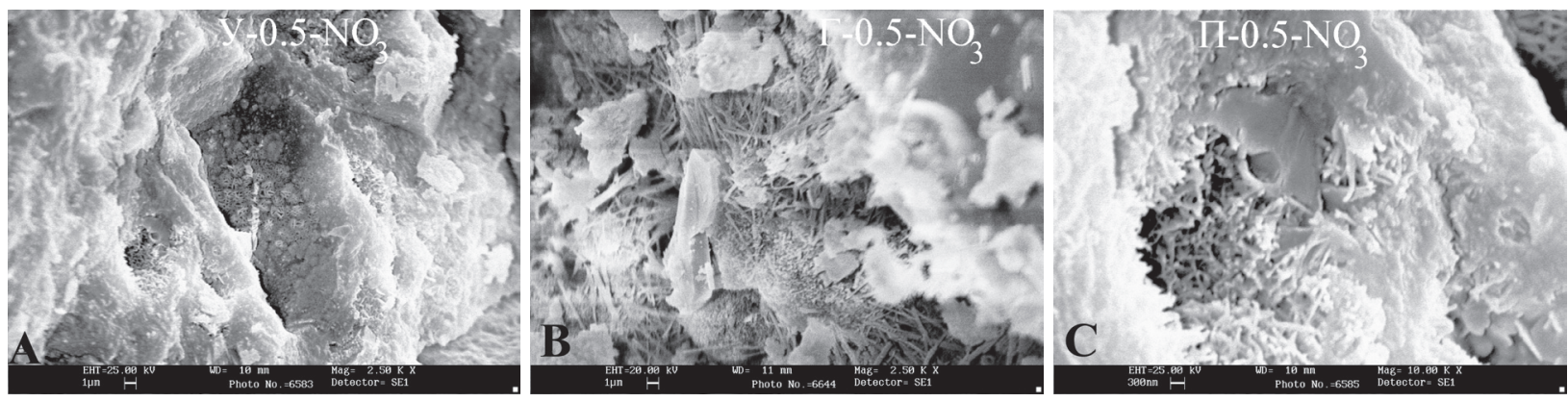

Рис. 3. Новообразования в порах бетона после 0.5 года воздействия азотной кислоты (SEM LEO-420). Увеличение $2500(\mathrm{~A}, \mathrm{~B})$ и 10000 (С).

Fig. 3. Newly formed phases in the concrete pores after 0.5 years of exposure to nitric acid (SEM LEO-420). Magnification $2500(\mathrm{~A}, \mathrm{~B})$ and $10000(\mathrm{C})$.

тых сфер или пластинчатых кристаллов, и хаотически, образуя войлокообразные текстуры. Упрочнение структуры цементного камня в этом случае происходит за счет замоноличивания пор и усиления сцепления в контактной зоне бетона. Это в условиях химической агрессии способствует кольматации порового пространства и контактной зоны между заполнителем и цементной матрицей бетона, повышая долговечность последнего (Рахимбаев, 2012).

Исследованием продуктов гидратации с помощью РФА установлено, что в контактной зоне «заполнитель - цементный камень» присутствуют типичные гидросиликаты кальция типа CHS (B), гидроксид кальция, гидрогранаты и гидроалюминаты кальция, карбонат кальция. Никаких новых образований, в том числе вызванных присутствием ионов $\mathrm{CI}, \mathrm{SO}_{4}{ }^{2-}$ и $\mathrm{NO}_{3}$, в контактной зоне исследуемых бетонов не выявлено. Дериватографическим анализом также не зарегистрировано никаких специфических эффектов в исследованных образцах бетонов, хранившихся в агрессивных условиях.

\section{Выводы}

1. Прочностными испытаниями бетонов на заполнителях из уртита, гранита и кварцевого песка, а также уртита и гранита с добавкой золы Апатитской ТЭЦ после 1 года воздействия агрессивных сред установлено, что во всех жидких средах бетоны на всех видах заполнителей увеличили значения прочности как при изгибе, так и при сжатии. Введение золы и тепловая обработка повышают прочность бетонов, особенно состава на уртитовом заполнителе. Результаты испытаний свидетельствует о коррозионной стойкости исследуемых бетонов.

2. Микроскопическими исследованиями внутренней структуры бетонов установлено, что во всех образцах бетонов после 0.5 года воздействия агрессивных сред в зоне контакта заполнителя с цементом наблюдается так называемая «реакционная кайма», свидетельствующая о происходящих химических процессах в зоне контакта. В целом микроскопическими исследованиями не выявлено каких-либо деструктивных изменений в структуре ни у одного из исследуемых образцов.

3. Изучением структуры бетонов с помощью сканирующей микроскопии подтверждено, что в исследованных образцах бетонов при воздействии агрессивных сред имеет место интенсификация процесса фазообразования вторичных продуктов. Данные новообразования (комальтанты) являются малорастворимыми продуктами коррозии и осаждаются в зоне контакта цемента с заполнителем и порах бетона, что замедляет диффузию агрессивных агентов. Установлено, что исследованные заполнители по степени взаимодействия с гидроксидом кальция поровой жидкости бетона являются активными в ряду уртит > гранит > кварцевый песок. Проведенные исследования позволяют заключить, что структура бетона на нефелинсодержащих заполнителях - уртитах - не только практически не отличается от таковой на традиционных заполнителях, но и является более прочной и плотной за счет улучшенной контактной зоны.

Работа выполнена в рамках темы НИР ИХТРЭМС КНЦ РАН № 0226-2019-0068. 


\section{Литература}

1. Белогурова Т.П., Крашенинников О.Н., Рояк Г.С. и др. О реакционной способности вскрышных пород рудников ПО «Апатит» // Физико-химические основы переработки и применения минерального сырья. Апатиты: КНЦ АН СССР. 1990. С. 32-35.

2. Белогурова Т.П., Крашенинников О.Н. Утилизация вскрышных пород Хибинских апатитонефелиновых месторождений в строительстве // Строительные материалы. 2004. № 6. С. 32-35.

3. Белогурова Т.П., Нерадовский Ю.Н., Компанченко А.А. Коррозионная стойкость уртитов в жидких агрессивных средах // Труды Ферсмановской научной сессии ГИ КНЦ РАН. 2019. № 16. С. $23-27$.

4. Крашенинников О.Н., Белогурова Т.П., Цветкова Т.В. Влияние минерального состава уртитового заполнителя и условий твердения бетона на формирование контактной зоны // Комплексное использование минерального сырья в строительных и технических материалах. Апатиты: КНЦ АН СССР. 1989. C. $22-25$.

5. Рахимбаев Ш.М. Кинетика процессов кольматации при химической коррозии цементных систем // Бетон и железобетон. 2012. № 6. С. 16-17.

6. Рахимбаев Ш.М., Толыпина Н.М. Кислотостойкий бетон с эффективным активным заполнителем // Бетон и железобетон. 2011. № 4. С. 24-26. 